\title{
Inhibition of lentivirus replication by aqueous extracts of Prunella
} vulgaris

\author{
Melinda A Brindley ${ }^{1}$, Mark P Widrlechner ${ }^{2}$, Joe-Ann McCoy²,5, \\ Patricia Murphy ${ }^{3}$, Cathy Hauck ${ }^{3}$, Ludmila Rizshsky ${ }^{4}$, Basil Nikolau ${ }^{4}$ and \\ Wendy Maury*1
}

\begin{abstract}
Address: ${ }^{1}$ Dept. Microbiology, University of Iowa, Iowa City, IA 52242, USA, ${ }^{2}$ US Department of Agriculture-Agricultural Research Service, North Central Regional Plant Introduction Station (MPW), Ames, IA 50011, USA, ${ }^{3}$ Department of Food Science and Human Nutrition, Iowa State University, Ames, IA 50011, USA, ${ }^{4}$ Department of Biochemistry, Biophysics and Molecular Biology, Iowa State University, Ames, IA 50011, USA and ${ }^{5}$ Bent Creek Institute/NCSU, The North Carolina Arboretum, 100 Frederick Law Olmsted Way, Asheville, NC 28806-9315, USA

Email: Melinda A Brindley - melinda.brindley@gmail.com; Mark P Widrlechner - Mark.Widrlechner@ARS.USDA.GOV; JoeAnn McCoy - Jmccoy@NCARBORETUM.ORG; Patricia Murphy - pmurphy@iastate.edu; Cathy Hauck - cchauck@iastate.edu; Ludmila Rizshsky - ludmilar@iastate.edu; Basil Nikolau - dimmas@iastate.edu; Wendy Maury* - wendy-maury@uiowa.edu

* Corresponding author
\end{abstract}

Published: 20 January 2009

Virology Journal 2009, 6:8 doi:10.1186/1743-422X-6-8

This article is available from: http://www.virologyj.com/content/6/1/8

(c) 2009 Brindley et al; licensee BioMed Central Ltd.

This is an Open Access article distributed under the terms of the Creative Commons Attribution License (http://creativecommons.org/licenses/by/2.0), which permits unrestricted use, distribution, and reproduction in any medium, provided the original work is properly cited.

\begin{abstract}
Background: Various members of the mint family have been used historically in Chinese and Native American medicine. Many of these same family members, including Prunella vulgaris, have been reported to have anti-viral activities. To further characterize the anti-lentiviral activities of $P$. vulgaris, water and ethanol extractions were tested for their ability to inhibit equine infectious anemia virus (EIAV) replication.

Results: Aqueous extracts contained more anti-viral activity than did ethanol extracts, displaying potent anti-lentiviral activity against virus in cell lines as well as in primary cell cultures with little to no cellular cytotoxicity. Time-of-addition studies demonstrated that the extracts were effective when added during the first four $h$ of the viral life cycle, suggesting that the botanical constituents were targeting the virion itself or early entry events. Further analysis revealed that the extracts did not destroy EIAV virion integrity, but prevented viral particles from binding to the surface of permissive cells. Modest levels of anti-EIAV activity were also detected when the cells were treated with the extracts prior to infection, indicating that anti-EIAV botanical constituents could interact with both viral particles and permissive cells to interfere with infectivity. Size fractionation of the extract demonstrated that eight of the nine fractions generated from aqueous extracts displayed anti-viral activity. Separation of ethanol soluble and insoluble compounds in the eight active fractions revealed that ethanol-soluble constituents were responsible for the anti-viral activity in one fraction whereas ethanol-insoluble constituents were important for the anti-viral activity in two of the other fractions. In three of the five fractions that lost activity upon sub-fractionation, anti-viral activity was restored upon reconstitution of the fractions, indicating that synergistic anti-viral activity is present in several of the fractions.
\end{abstract}

Conclusion: Our findings indicate that multiple Prunella constituents have profound anti-viral activity against EIAV, providing additional evidence of the broad anti-viral abilities of these extracts. The ability of the aqueous extracts to prevent entry of viral particles into permissive cells suggests that these extracts may function as promising microbicides against lentiviruses. 


\section{Background}

P. vulgaris, commonly known as "self-heal", is a low-growing perennial herb with worldwide distribution. The herb is a member of the mint family Lamiaceae. Salves, teas, and extracts made from the plant have been used to treat wounds, inflammation, and other minor body disorders by both the Chinese and Native Americans [1,2].

Various bioactive constituents have been identified in extracts of $P$. vulgaris. These include phenolic constituents, complex carbohydrates and more hydrophobic metabolites such as triterpenes. The abundant polysaccharides present in $P$. vulgaris are readily extracted by water and have a number of reported biological activities $[3,4]$, and several of the triterpenes have been identified with significant anti-inflammatory activity [5]. Large quantities of anti-oxidants are known to be present in aqueous Prunella extracts with the polyphenolic compound, rosmarinic acid, being one of the most abundant of these constituents [6,7]. Rosmarinic acid has also been shown to have anti-inflammatory activity as a result of specific inhibition of $\mathrm{T}$ cell signaling and an impact on glucose metabolism [8-10].

Prunella extracts have been reported to contain anti-viral and anti-bacterial properties, although constituents responsible for these activities are incompletely characterized to date $[7,11,12]$. Recent research has confirmed that anionic polysaccharides in aqueous extracts of $P$. vulgaris can decrease the replication of herpes simplex virus- 1 and -2 (HSV-1, HSV-2) by preventing viral binding to cells [11,13-15]. P. vulgaris extracts have also been shown to contain anti-HIV activity. Studies have identified inhibition of HIV infection at steps of virus binding [16], fusion [17], reverse transcription [12], integration [18], and protease function [19]. Many of these studies identified Prunella antiviral activity through high through-put screens for specific viral protein targets in in vitro assays. While constituents in Prunella may be effective against these numerous anti-HIV targets in vitro, inhibition of the specific targets responsible for anti-HIV activity of Prunella in cells remains unclear. Identification of constituents of $P$. vulgaris that confer the inhibition to HIV-1 is limited to the water soluble, $10 \mathrm{kDa}$ polysaccharide, Prunellin, that interferes with HIV-1 virion binding to permissive cells $[16,20]$. Rosmarinic acid extracted from other botanicals has proved effective against HIV-1 integrase [21], but the role of this polyphenol in the anti-retroviral activities of Prunella extracts has not been explored. Additional members of the Lamiaceae, such as peppermint and lemon balm, are also known to have anti-viral activities, but specific constituents responsible for those activities remain unidentified $[13,22]$.
In this study we sought to examine the breadth of the antilentiviral activity of water and ethanol extracts from several P. vulgaris accessions by investigating their ability to inhibit replication of equine infectious anemia virus (EIAV). Water extracts of two of the accessions that had the greatest anti-viral activity were determined to interfere with virus binding and uptake. Our studies identified several different constituents present in the aqueous extracts that had significant activity against EIAV. Our findings suggest that this extract may serve as an effective microbicide against lentiviruses.

\section{Methods}

\section{Growth and collection of $\mathbf{P}$. vulgaris accessions}

All Prunella vulgaris plant samples were provided by the North Central Regional Plant Introduction Station (NCRPIS, Ames, IA) of the Agricultural Research Service of the U.S Department of Agriculture. All samples utilized in experiments were produced from populations collected from North Carolina or Missouri in October, 2004 on a collection trip sponsored by the USDA/NCRPIS/ISU/NIH. Both seed and voucher specimens were collected from all original sites and specimens were keyed to species [31]. Seeds from accessions Ames 27664, 27665, 27666 and 27748 were germinated in Petri plates at $25^{\circ} \mathrm{C}$, transferred to flats in a greenhouse $\left(20-25^{\circ} \mathrm{C}\right)$ before final field transfer into individual control pollinated screened cages in Ames, IA. Upper flowering portions of 14 month old plants were harvested, dried for 1 week at $38{ }^{\circ} \mathrm{C}$ in a forced-air dryer with constant humidity and ground (RTCR301ULTRAB) for analysis. All voucher specimens representing both original and regenerated populations are stored in the Ada Hayden Herbarium, Iowa State University (Ames, IA: ISC). Seeds representing both original and regenerated populations are stored at the USDA NCRPIS under controlled conditions $\left(-20^{\circ} \mathrm{C}, 4^{\circ} \mathrm{C}\right.$ for regenerated samples). Information about the specific provenance of all accessions used for the experiments is available via the Germplasm Resources Information Network database at http://www.ars-grin.gov/npgs/acc/acc queries.html.

\section{Extraction and fractionation of $P$. vulgaris}

All glassware was heated at $200^{\circ} \mathrm{C}$ for $2 \mathrm{~h}$ to destroy endotoxin.

\section{Water extraction}

One hundred $\mathrm{mL}$ of boiling, endotoxin-free water was poured over $6 \mathrm{~g}$ of dried $P$. vulgaris. The plant material was steeped, with stirring, for $1 \mathrm{~h}$ and filtered through a G6 glass fiber circle (Fisher Scientific) in a Buchner funnel. The filtrate was centrifuged at $10,000 \times \mathrm{g}$ for 20 minutes to remove any additional particulates. The extract was lyophilized, weighed, and re-dissolved in DMSO. 


\section{Ethanol extraction}

Six g of dried P. vulgaris was extracted with $500 \mathrm{~mL}$ of $95 \%$ ethanol via Soxhlet for $6 \mathrm{~h}$. The extract was filtered, dried by rotary evaporation at $<40^{\circ} \mathrm{C}$ and then lyophilized. Extracts were resuspended in DMSO.

\section{Size-exclusion fractionation}

Two g of dry Prunella water extract, dissolved in $10 \mathrm{~mL}$ endotoxin-free water, was loaded onto a $2.5 \times 75 \mathrm{~cm}$ Sephacryl 100HR column. Endotoxin-free water was used to elute the size-exclusion column. Two L of eluent was collected in $10 \mathrm{~mL}$ fractions collected for $72 \mathrm{~h}$. Absorbance at $210 \mathrm{~nm}$ was measured for all fractions to monitor separation efficiency and identify peaks. Nine peaks were detected. Fractions composing these peaks were pooled and concentrated by lyophylization. Fractions were resuspended in endotoxin-free water.

\section{Endotoxin levels of extracts and fractions}

All extracts and fractions were evaluated for endotoxin using the Chromogenic Limulus Amebocyte Lysate Test kit per manufacturer's instructions (Cambrex Bioscience Inc.). This assay is able to detect concentrations of endotoxin of $0.007 \mathrm{EU} / \mathrm{mL}$ or greater. All extracts had $<0.007$ $\mathrm{EU} / \mathrm{mL}$ at the highest concentrations used in these studies. The fractions had slightly higher endotoxin levels; the highest amount of endotoxin present in the fractions when diluted for these studies was $0.023 \mathrm{EU} / \mathrm{mL}$.

\section{Separation of ethanol soluble and insoluble constituents in the size fractionated fractions}

Sufficient $100 \%$ ethanol was added to each fraction to yield a 95\% ethanol solution. These fractions were placed in a rotary shaker at room temperature for $1 \mathrm{~h}$. Fractions were centrifuged at $10,000 \times \mathrm{g}$ for $20 \mathrm{~min}$. The ethanolsoluble supernatant was decanted, and the ethanol-insoluble pellet was redissolved in endotoxin-free water. Each sub-fraction was lyophilized and weighed and resuspended in endotoxin-free water.

\section{Cells and viral strains}

Equine dermis cells (ED cells) (ATCC CCL57) were maintained in high glucose DMEM with 15\% fetal calf serum (FCS). Primary equine umbilical vein endothelial cells (eUVEC) were also used in the EIAV studies and were maintained in high glucose DMEM with 40\% FCS. All media were supplemented with penicillin and streptomycin.

Stocks of EIAV were generated in ED cells. Viral stocks of EIAV $_{\text {WSU5 }}$ [23], EIAV MA-1 $_{\text {[24], EIAV }}$ vMA-1c $[25]$, EIAV $_{\text {SP19 }}$ [26], and EIAV $_{\mathrm{Th} 1}$ [24] from ED cell supernatants were harvested from cells that were $>95 \%$ positive for EIAV antigen as determined by EIAV antigen immunostaining. Supernatants were centrifuged for $5 \mathrm{~min}$ at $13,500 \times \mathrm{g}$ to remove cell debris, aliquoted, and frozen at $-80^{\circ} \mathrm{C}$ until needed. Viral titers were determined by infection of ED cells using the single round of infection assay described below.

\section{Viral infection and time-of-addition studies Inhibition of infectivity studies}

All extracts were resuspended in DMSO, and fractions and sub-fractions were resuspended in water. 250 infectious particles of EIAV were combined with the concentrations of extracts, fractions or sub-fractions as noted in the figures. The amount of DMSO was adjusted so that equivalent concentrations of DMSO were present in all wells within an experiment. No more than 1.5\% DMSO was used, as ED cell cytotoxicity was observed at higher DMSO concentrations. In experiments where extracts were studied, the quantity of DMSO was carefully controlled. As the total concentration of botanical constituents varied slightly between the different accession extracts, the quantity of constituents assayed was slightly different for each accession. The constituent concentrations that were used are noted in Table 1 and in the relevant figure legends. The extract and virus mixture were added to $5 \times 10^{4}$ cells/well of ED cells or eUVEC in a 48-well format resulting in a multiplicity of infection (MOI) of $\sim 0.005$. The cells were maintained for $40 \mathrm{~h}$. Cells were fixed with $75 \%$ acetone/ $25 \%$ water fixation and immunostaining of the cells for EIAV antigens was performed as previously described [27]. The EIAV antigen-positive cells within the infected cell monolayer were counted and titers determined. $\mathrm{IC}_{50}$ and $\mathrm{IC}_{90}$ concentrations were determined using TableCurve software (Systat Academic).

\section{Inhibition of entry studies}

EIAV $_{\text {WSU5 }}$ was added to ED cells at an MOI of 0.005 in ED media. DMSO or extracts of P. vulgaris Ames 27664 or Ames 27748 extract was added to the well at 0, 1, 2, 3, 4, 6 , and $8 \mathrm{~h}$ following infection at a final concentration of $0.2 \%$ DMSO $(66 \mu \mathrm{g} / \mathrm{mL}$ of Ames 27664 or $62.4 \mu \mathrm{g} / \mathrm{mL}$ of Ames 27748). Forty h following infection the cells were fixed, immunostained for EIAV antigen and the EIAV positive cells enumerated.

\section{Cell bound EIAV studies}

EIAV $_{\text {WSU5 }}$ was bound to ED cells at $4{ }^{\circ} \mathrm{C}$ for $1 \mathrm{~h}$ to permit binding, but prevent virion internalization. The cells were warmed to $37^{\circ} \mathrm{C}$ and DMSO or Prunella extract was added to the well at $0,1,2,3,4,6$, and $8 \mathrm{~h}$ following temperature shift at a final concentration of $0.2 \%$ DMSO $(66 \mu \mathrm{g} / \mathrm{mL}$ of Ames 27664 or $62.4 \mu \mathrm{g} / \mathrm{mL}$ of Ames 27748). Forty h following infection the cells were fixed, immunostained for EIAV antigens and EIAV-positive cells enumerated. 
Table I: Concentrations of Prunella stocks

\begin{tabular}{|c|c|}
\hline Botanical & $\begin{array}{c}\text { Concentration } \\
(\mathrm{mg} / \mathrm{mL})\end{array}$ \\
\hline Extracts:* & 33.0 \\
\hline Ames 27664 - water & 21.1 \\
\hline Ames 27665 - water & 29.8 \\
\hline Ames 27666 - water & 31.2 \\
\hline Ames 27748 - water & 33.4 \\
\hline Ames 27664 - ethanol & 34.6 \\
\hline Ames 27665 - ethanol & 32.1 \\
\hline Ames 27666 - ethanol & 33.7 \\
\hline \multicolumn{2}{|l|}{ Ames 27748 - ethanol } \\
\hline Fractions: & 100 \\
\hline Fraction I & 100 \\
\hline Fraction 2 & 100 \\
\hline Fraction 3 & 100 \\
\hline Fraction 4 & 100 \\
\hline Fraction 5 & 100 \\
\hline Fraction 6 & 100 \\
\hline Fraction 7 & 100 \\
\hline Fraction 8 & 100 \\
\hline Fraction 9 & 100 \\
\hline \multicolumn{2}{|l|}{ Sub-fractions: } \\
\hline Ethanol soluble I & 89.1 \\
\hline Ethanol soluble 2 & 40.6 \\
\hline Ethanol soluble 3 & 53.0 \\
\hline Ethanol soluble 4 & 41.0 \\
\hline Ethanol soluble 5 & 29.1 \\
\hline Ethanol soluble 6 & 93.9 \\
\hline Ethanol soluble 7 & 63.5 \\
\hline Ethanol soluble 8 & 19.7 \\
\hline Ethanol soluble 9 & 70.5 \\
\hline Ethanol insoluble I & 10.9 \\
\hline Ethanol insoluble 2 & 59.4 \\
\hline Ethanol insoluble 3 & 46.9 \\
\hline Ethanol insoluble 4 & 59.0 \\
\hline Ethanol insoluble 5 & 70.9 \\
\hline Ethanol insoluble 6 & 6.2 \\
\hline Ethanol insoluble 7 & 36.5 \\
\hline Ethanol insoluble 8 & 80.3 \\
\hline Ethanol insoluble 9 & 29.6 \\
\hline
\end{tabular}

$*=$ all solvent used in the extraction procedure was removed from the extracts and extract material was resuspended in DMSO. All fractions and subfractions were resuspended in sterile water.

\section{Internalization studies}

EIAV $_{\text {Wsu5 }}$ was bound to ED cells at $4^{\circ} \mathrm{C}$ for $1 \mathrm{~h}$ to permit binding, but prevent virion internalization. Unbound virus was removed, new media replaced, and the cells shifted to $37^{\circ} \mathrm{C}$ to promote internalization. At $0,1,2,4$, and $6 \mathrm{~h}$ following temperature shift, the cells were washed briefly in citrate acid buffer ( $\mathrm{pH}$ 3.0) to inactivate any non-internalized virions. The citrate buffer was removed and cells were washed twice, and medium contain $0.2 \%$ of DMSO, $66 \mu \mathrm{g} / \mathrm{mL}$ of Ames 27664 extract, or $62.4 \mu \mathrm{g} /$ $\mathrm{mL}$ of Ames 27748 extract was added to determine if the extracts had any inhibitory effect on virions that had already been internalized.

\section{Virion stability studies}

EIAV viral stock was incubated in DMEM with $10 \%$ fetal calf or DMEM $10 \%$ fetal calf plus $132 \mu \mathrm{g} / \mathrm{mL}$ of Ames 27664 extract or $126 \mu \mathrm{g} / \mathrm{mL}$ of Ames 27748 extract. The virus stock was maintained at $37^{\circ} \mathrm{C}$ and used to infect ED cells at various time points following extract exposure. The final concentration of Prunella when diluted on the cells was $0.44 \mu \mathrm{g} / \mathrm{mL}$ of Ames 27664 extract or $0.42 \mu \mathrm{g} / \mathrm{mL}$ of Ames 27748 extract. At $40 \mathrm{~h}$ following initiation of infection, the cells were fixed and immunostained for the production of EIAV proteins.

\section{Viral binding assay}

Virus was mixed with $132 \mu \mathrm{g} / \mathrm{mL}$ of Ames 27664 extract or $126 \mu \mathrm{g} / \mathrm{mL}$ of Ames 27748 extracts (final concentration of $0.4 \%$ DMSO) or fractions $(100 \mathrm{ug} / \mathrm{mL})$ and incubated with ED cells (MOI of 2 ) at $4^{\circ} \mathrm{C}$ for $2 \mathrm{~h}$ to permit binding, but prevent virion internalization. Unbound virions were removed and cells were washed with phosphate buffered saline (PBS) three times to ensure all unbound virions were removed from the cells. Each well was lysed in $50 \mu \mathrm{L}$ of lysis buffer (50 mM Tris $\mathrm{HCl}(\mathrm{pH} 8), 120 \mathrm{mM} \mathrm{NaCl}$, and $0.5 \% \mathrm{NP} 40$, and $1 \mathrm{U} / \mathrm{mL}$ of protease inhibitor cocktail (Sigma). The lysates were analyzed by immunoblotting for the presence of viral capsid to indicate virus binding as described below. Blots were re-probed for cellular $\beta$-tubulin to normalize for cellular input.

\section{Inhibition of virion infectivity studies}

$10^{5}$ infectious particles of EIAV ${ }_{\text {wsu5 }}$ were incubated at room temperature for $10 \mathrm{~min}$ with $P$. vulgaris Ames accession 27664 aqueous extract. Following the incubation, dilutions of the incubated virus were added to ED cells in a 48-well format and appropriate concentrations of extract were maintained on the cells for the duration of the experiment. Cells were fixed at $40 \mathrm{~h}$ following infection and immunostained as described above. Wells with serial dilutions containing between 10 and 250 virus positive cells were enumerated and back-calculations were made to obtain the numbers of infectious units of virus/ $\mathrm{mL}$.

\section{Immunoblotting}

Cell lysates were run on NuPAGE Novex Bis-Tris Mini Gels (Invitrogen) and transferred to nitrocellulose. EIAV capsid was detected using the 2085 sera (1:10000) and secondary anti-horse antisera $(1: 10000)$ that was used for immunostaining. Tubulin was detected by the E7 monoclonal antibody (1:2000) (NIH Developmental Studies Hybridoma Bank, University of Iowa) and sheep anti-mouse HRP secondary (GE Healthcare) (1:50,000). All immunoblots were visualized using WestDura (Pierce). 


\section{Sucrose-gradient centrifugation}

Sucrose step gradients were prepared by layering $250 \mu \mathrm{L}$ aliquots of decreasing concentrations of sucrose $(20 \%-$ $60 \%$ ) into $3 \mathrm{~mL}$ ultra centrifugation tubes. The gradients were allowed to equilibrate at $4{ }^{\circ} \mathrm{C}$ for at least $3 \mathrm{~h}$. Virions were treated with extracts $(0.4 \%), 0.5 \%$ Triton-X 100 or DMSO for $1 \mathrm{~h}$ at $37^{\circ} \mathrm{C}$ and loaded onto the top of the gradients. Tubes were centrifuged for $16 \mathrm{~h}$ at $40,000 \mathrm{rpm}$ in a SW60 rotor at $4{ }^{\circ} \mathrm{C}$ and stopped without a brake. Two hundred and fifty microliter aliquots were collected beginning from the top of the tube and stored at $-80^{\circ} \mathrm{C}$ until analyzed by immunoblotting.

\section{Cell viability studies}

Cells were plated and treated with extracts as described above. Forty h following treatment cell viability was monitored by ATPLite Assay (Packard Biosciences) per manufacturer's instructions.

\section{Statistical analysis}

Studies were performed at least three independent times except where noted in the figure legends. Means and standard errors of the mean are shown. Student's t-test was used to evaluate the statistical differences between treatments, utilizing the two-tailed distribution and twosample equal-variance conditions. P-values were assessed by comparing the level of infectivity with treatment to the level of cytoxicity seen with that same treatment. P-values for viability were assessed by comparing the level of viability with treatment to the level of viability seen with DMSO or control. A significant difference was determined by a p-value of $<0.05$ and significance was identified in each figure. If the $\mathrm{p}$-value was $>0.05$, the data were not considered statistically significantly different.

\section{Results \\ Aqueous extracts from P. vulgaris inhibit EIAV infectivity without significant cell toxicity}

Water and ethanol extractions were prepared from four accessions of Prunella vulgaris. Three of the accessions (Ames 27664, 27665 and 27666) were collected in western North Carolina; Ames 27748 was collected in Missouri. Ames 27664 and 27748 were obtained from disturbed roadside areas whereas the other two accessions were collected from more remote, forested habitats. These extracts were screened for their ability to inhibit EIAV ${ }_{\text {WSU5 }}$ in a single-round infection assay. Extracts and virus were diluted in media and immediately incubated with cells. Forty h following infections, the cells were fixed, immunostained for expression of EIAV antigens and antigenpositive cells enumerated to determine the level of viral infection (Fig. 1). Although both ethanol and water extracts demonstrated some ability to inhibit EIAV ${ }_{\text {WSU5, }}$ water extracts contained the largest quantities of anti-viral activity. At the concentrations tested, all extracts had little

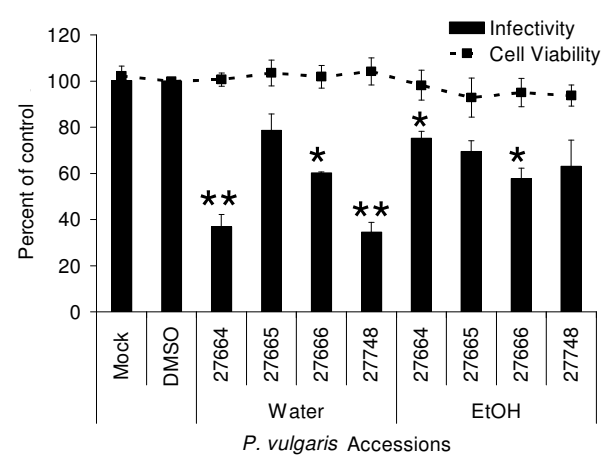

Figure I

Water extracts of $P$. vulgaris inhibit lentiviral infectivity with low cell toxicity. DMSO, water extracts and ethanol extracts of $P$. vulgaris were diluted in media to $0.2 \%$ (water extracts: $66 \mu \mathrm{g} / \mathrm{mL}$ of Ames 27664, $42.2 \mu \mathrm{g} / \mathrm{mL}$ of Ames $27665,59.6 \mu \mathrm{g} / \mathrm{mL}$ of Ames 27666 , or $62.4 \mu \mathrm{g} / \mathrm{mL}$ of Ames 27748 and ethanol extracts: $66.8 \mu \mathrm{g} / \mathrm{mL}$ of Ames $27664,69.2 \mu \mathrm{g} / \mathrm{mL}$ of Ames 27665, 64.2 $\mu \mathrm{g} / \mathrm{mL}$ of Ames 27666 , or $67.4 \mu \mathrm{g} / \mathrm{mL}$ of Ames 27748). Equivalent quantities of EIAV $\mathrm{WSU}_{\text {WS }}$ were added to each well of ED cells along with the diluted extracts. Forty $h$ following infection, cells were fixed and immunostained for viral antigen. Cell-viability studies were performed in parallel. Cell viability and virus infectivity are shown as a ratio of the values in the presence of the extracts divided by the DMSO control. Shown are the averages and standard errors of three experiments performed in triplicate. *, $\mathrm{p}<0.05$; **, $\mathrm{p}<0.001$.

or no cytotoxicity. Aqueous extracts of Ames 27664 and 27748 had the most significant anti-viral effect against EIAV. While the aqueous extracts of Ames 27664 and 27748 contained slightly greater concentrations of constituents than the other two aqueous extracts, these modestly higher concentrations could not solely explain the better activity of these accessions since serial dilutions of extracts from Ames 27664 and 27748 still had more antiviral activity against EIAV than undiluted aqueous extracts from Ames 27665 and 27666 (Additional file 1). Thus, aqueous extracts of Ames 27664 and 27748 were further studied to determine the block in EIAV replication.

To ensure that the effects seen in the initial study were not viral-strain or cell-type specific, water extracts of $P$. vulgaris Ames 27664 and 27748 were tested for inhibition of EIAV replication in primary cells. Primary equine umbilical vein endothelial (eUVEC) cells were infected with EIAV $_{\text {WSU5 }}$ in the presence of the extracts and EIAV infection was inhibited to a similar degree as observed in ED cells (Fig. 2A). Extracts also showed no cytotoxicity in the primary cells. 

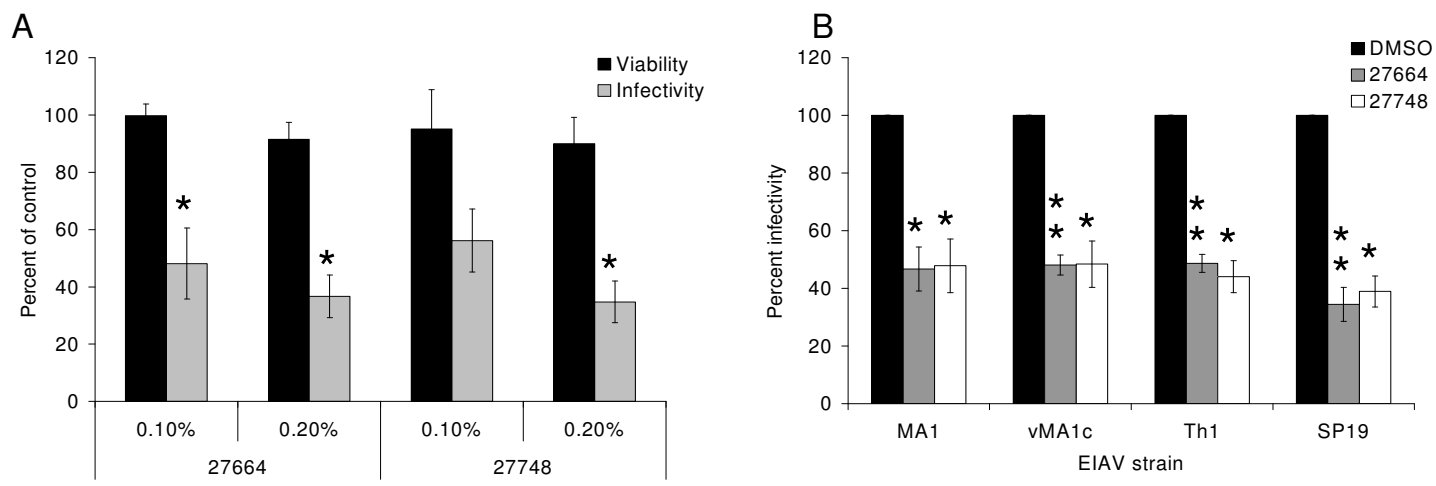

\section{Figure 2}

EIAV inhibition by water extracts of Prunella Ames 27664 and 27748 is not cell type or strain specific. A) EIAV infections of UVECs. DMSO and water extracts of Ames 27664 and 27748 were diluted in media to $0.1 \%(33 \mu \mathrm{g} / \mathrm{mL}$ of Ames

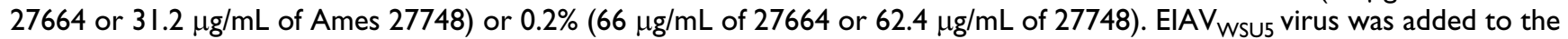
diluted extracts and immediately used to infect eUVECs. B) Inhibition of infection of four EIAV strains was evaluated in ED cells in the presence of $0.2 \%$ P. vulgaris aqueous extracts of Ames 27664 and 27748 or DMSO. Forty h following infection, cells were immunostained for EIAV antigen. Parallel cultures that were treated with extract, but not infected were evaluated for cell viability. Shown are the ratios of the values in the presence of the extracts divided by the DMSO control. Shown are the averages and standard errors of three experiments performed in triplicate. $*, p<0.05 ; * *, p<0.001$.

Aqueous extracts of Ames 27664 and 27748 were also tested for their ability to inhibit a variety of EIAV strains (Fig. 2B). Two tissue-culture adapted strains, EIAV ${ }_{\mathrm{MA1}}$ and EIAV $_{\text {SP19, }}$ as well as a field isolate, EIAV $_{\text {Th1 }}$, and a variant superinfecting strain, EIAV $\mathrm{VMA1}_{\mathrm{c}}$, were effectively inhibited by the extracts. Previous studies have demonstrated that EIAV $_{\text {vMA1c }}$ enters ED cells through an alternative pathway compared to its parental strain EIAV $_{\text {MA1 }}$ [28-30].
EIAV $_{\mathrm{vMA1c}}$ enters ED cells through plasma membrane fusion whereas EIAV $\mathrm{MA}_{\mathrm{M}}$ and other wild-type strains of EIAV enter ED cells through interaction with the cellular receptor ELR1 that is mediated by a low-pH dependent, clathrin-mediated endocytosis event. The observation that the $P$. vulgaris extracts inhibit both the wild-type strains and variant strain equivalently suggest that Prunella antiviral activity is broadly inhibitory and does not block spe-
A

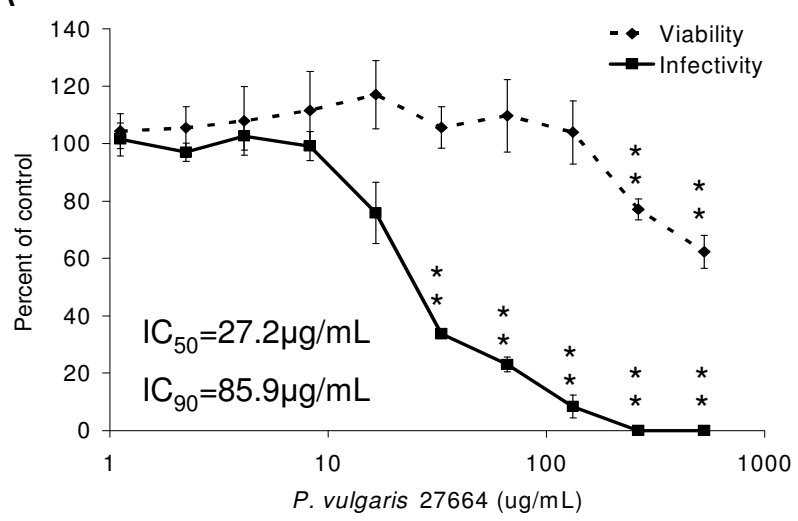

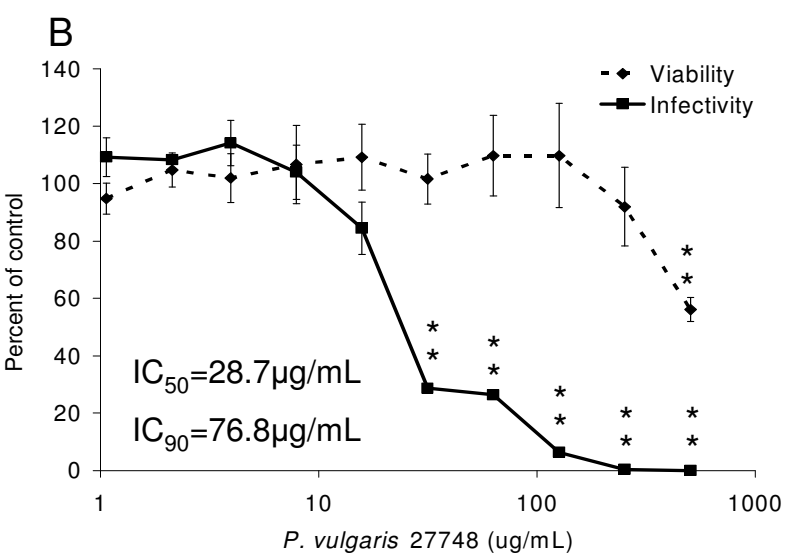

Figure 3

Dose dependent inhibition of aqueous extracts of Prunella Ames 27664 and 27748 to inhibit EIAV infection. Increasing concentrations of $P$. vulgaris aqueous extracts A) Ames 27664 and B) Ames 27748 were evaluated for the ability to

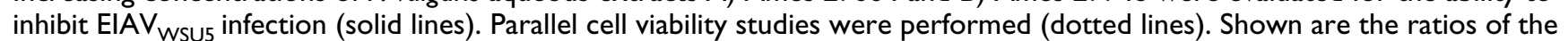
values in the presence of the extracts divided by the DMSO control. Shown are the averages and standard errors of three experiments performed in triplicate. ${ }^{* *}, \mathrm{p}<0.001$. 
cific viral-entry events, such as viral glycoprotein/ELR1 interactions.

To examine the inhibition of the Prunella aqueous extracts more closely, dose response curves were generated and the concentrations of extracts required to inhibit $50 \%$ and $90 \%$ of viral infection $\left(\mathrm{IC}_{50}\right.$ and $\mathrm{IC}_{90}$, respectively) determined. Fifty percent of EIAV $V_{\text {Wsu }}$ infectivity is inhibited with $27.2 \mu \mathrm{g} / \mathrm{mL}$ of Prunella Ames 27664 and $28.7 \mu \mathrm{g} / \mathrm{mL}$ of Prunella Ames 27748, and ninety percent is inhibited by $85.9 \mu \mathrm{g} / \mathrm{mL}$ and $76.8 \mu \mathrm{g} / \mathrm{mL}$, respectively (Fig. 3A and $3 \mathrm{~B})$. While the dose of extract needed to inhibit $50 \%$ of cell viability $\left(\mathrm{LD}_{50}\right)$ could not be determined due to limited observed cytotoxicity, an approximate $40 \%$ reduction in viability was observed at the highest dose tested $(600$ $\mu \mathrm{g} / \mathrm{mL}$ ) suggesting that the therapeutic window (LC50/ IC50) was more than 20-fold.

\section{Prunella extracts primarily inhibit early steps in the EIAV life-cycle}

To determine step(s) during the viral life cycle that are inhibited by the extracts, time-of-addition experiments were performed. In the first set of experiments, ED cells were infected with $\mathrm{EIAV}_{\text {Wsus }}$ and at six time points following infection, aqueous extracts were added to the infected cells. Addition of extracts at 1-4 h following initiation of infection effectively inhibited virus replication with a decreasing impact of extract addition over time (Fig. 4A). We have previously shown that EIAV binds to cells within six h of infection [30]. Here we demonstrate that by six h, the addition of the extracts did not have a statistically significant effect on EIAV infectivity. This finding indicated that the inhibition by Prunella extract was occurring prior to or during virus entry.

Because the aqueous extracts were inhibiting early steps in the viral life-cycle, we sought to determine if the extracts interfered with entry steps either prior to or following virus binding to permissive cells. Virus was pre-bound to ED cells at $4{ }^{\circ} \mathrm{C}$ to permit binding, but prevent internalization. After the one $\mathrm{h}$ binding step, unbound virions were removed and the cells shifted to $37^{\circ} \mathrm{C}$ to promote internalization. Extracts were added at various times following the temperature shift to $37^{\circ} \mathrm{C}$. Under these conditions, our previous studies have demonstrated that EIAV is internalized from the surface of ED cells within four $h$ [29]. When EIAV was pre-bound, EIAV infectivity at early times of infection (1-4 h) was less sensitive to Prunella inhibition than when virus was not pre-bound (Fig. 4B and Table 2). For instance in the absence of a pre-binding step, the addition of Prunella extracts at $2 \mathrm{~h}$ resulted in $77 \%$ inhibition of infectivity. In contrast, if the virus was prebound, $53 \%$ of the virus was sensitive to Prunella inhibition. This finding suggested that constituents in Prunella aqueous extracts were interfering to some extent with virus binding to ED cells and a pre-binding step decreased the inhibition observed at early time points. However, smaller, but significant reduction in viral infectivity was also observed following a pre-binding step, indicating Prunella aqueous extracts interfere with post-binding events as well.

We also tested the ability of Prunella aqueous extracts to inhibit virions that have been internalized from the cell surface. Virions were bound to ED cells at $4^{\circ} \mathrm{C}$, unbound virions were removed, fresh media replaced and the cells shifted to $37^{\circ} \mathrm{C}$ to promote virion internalization. At 0,1 , 2,4 , and $6 \mathrm{~h}$ following $37^{\circ} \mathrm{C}$ temperature shift, the cells were treated with citric acid buffer that inactivates all virions remaining on the cell surface. The cells were washed and media containing DMSO or extracts added to the cells and maintained for the $40 \mathrm{~h}$ infection. Internalized virions were not impacted by Prunella extracts (Fig. 4C). In total, our data suggest that the Prunella extracts inhibit EIAV infectivity by interfering with virus binding and subsequent requisite steps that occur prior to virion internalization. However, once the virions are internalized, the extract was not inhibitory.

Next we wanted to determine if exposing the cells to the extracts, without exposing the virions, could inhibit EIAV replication. ED cells were incubated with the extracts for two h. The medium was changed and cells infected with EIAV $_{\text {Wsu5 }}$. Pre-exposure of cells to the extracts from Prunella Ames 27748 reduced the level of infectivity by $15 \%$ which was statitistically significantly different from the control (Fig. 5A). The modest inhibition observed with extracts of Ames 27664 was not found to be statistically significant because of larger amounts of experimental variation in studies performed with this extract. The limited antiviral activity found in this experiment is consistent with the time-of-addition studies, suggesting that

Table 2: Percent of virus added that is sensitive to Prunella extracts

Time of addition (hr)

\begin{tabular}{lccccccc}
\hline Treatment & $\mathbf{0}$ & $\mathbf{1}$ & $\mathbf{2}$ & $\mathbf{3}$ & $\mathbf{4}$ & $\mathbf{6}$ & $\mathbf{8}$ \\
\hline No pre-binding & 78 & 79 & 77 & 69 & 50 & 31 & 17 \\
\hline Pre bound virions & 72 & 52 & 53 & 32 & 34 & 29 & 18 \\
\hline Internalized virions & 0 & -1 & 7 & nd & 5 & -3 & nd
\end{tabular}

Percent of virions sensitive to the extracts was calculated by subtracting the infectivity in the presence of the extracts from the DMSO control at each time point. Data from the extracts 27666 and 27748 were averaged. nd, data not determined. 
A
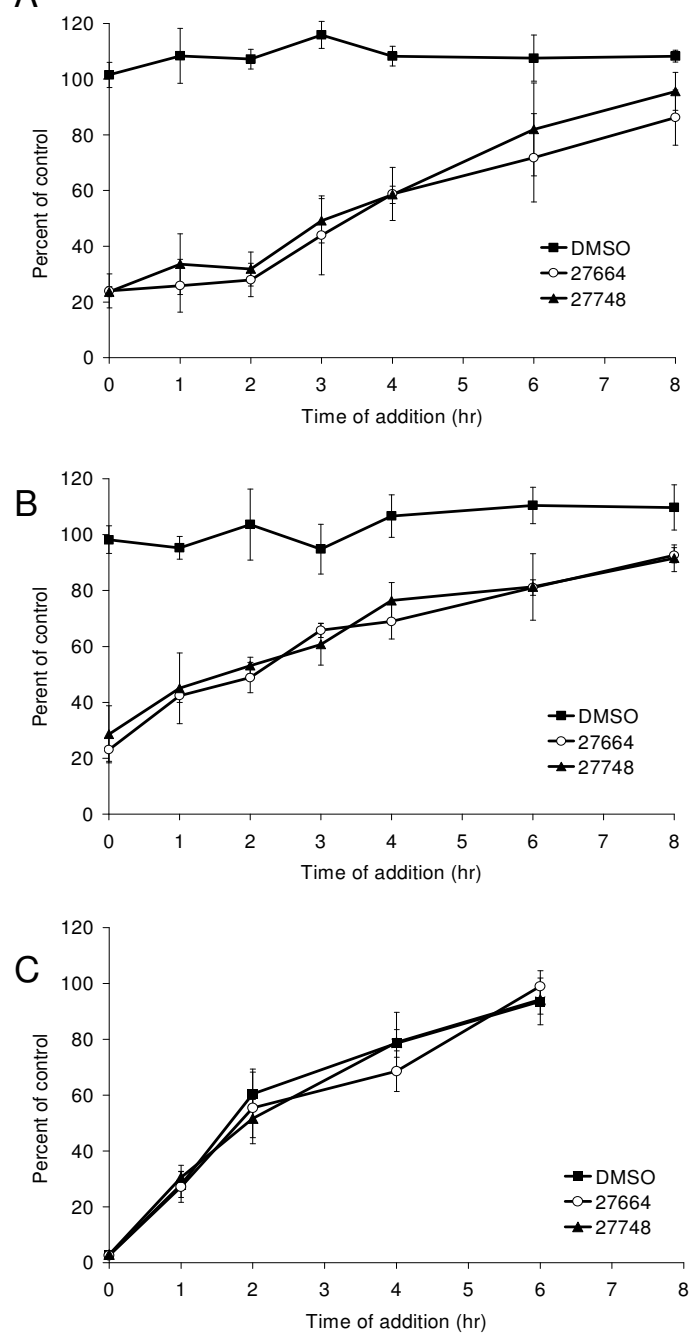

\section{Figure 4}

Early steps in the EIAV life cycle are inhibited by Prunella aqueous extracts. A) Time frame of extract inhibition of EIAV infection. ED cells were infected with EIAV wsu5 $_{5}$ virus and, at times noted following infection, DMSO, Ames 27664 extract, or Ames 27748 extract was added to the cells to a final concentration of $0.2 \%(66 \mu \mathrm{g} / \mathrm{mL}$ of Ames 27664 or $62.4 \mu \mathrm{g} /$ $\mathrm{mL}$ of Ames 27748). B) Time frame of extract inhibition of ElAV $\mathrm{wsU}_{5}$ that was previously bound to ED cells. Viral particles were bound to ED cells at $4^{\circ} \mathrm{C}$ for I $\mathrm{h}$. Unbound virus was removed and cells were shifted to $37^{\circ} \mathrm{C}$. At the times indicated, DMSO, Ames 27664 extract or Ames 27748 extract was added to the cells to a final concentration of $0.2 \%$. The percent of infected cells was determined by dividing the number of EIAV antigen positive cells in the presence of extract compared to the number of EIAV antigen positive cells in the presence of DMSO at time zero. C) Time frame of extract inhibition of EIAV ${ }_{\text {wsU5 }}$ following virion internalization. Virions were bound to ED cells at $4^{\circ} \mathrm{C}$ for $\mathrm{I} \mathrm{h}$, unbound virions were removed, fresh media was replaced, and cells were permitted to internalize at $37^{\circ} \mathrm{C}$. At the time points indicated, the cells were washed with citric acid buffer to inactivate any non-internalized virions, washed and media containing DMSO, Ames 27664 extract, or Ames 27748 extract was added (0.2\%). Data represent the average and standard error of three experiments performed in duplicate. Prunella extracts significantly decreased EIAV infectivity compared to DMSO control at $0,1,2,3$, and 4 h time points in panels A and B $(p<0.05)$. Differences observed at 6 and $8 \mathrm{~h}$ were not statistically significant. 
the extracts need to come in direct contact with the virions for the most robust inhibition.

To determine the reduction in particle infectivity by $P$. vulgaris extracts, we incubated $10^{5}$ infectious virions of EIAV $_{\text {Wsu5 }}$ with 25 to $100 \mu \mathrm{g} / \mathrm{mL}$ of extract for $10 \mathrm{~min}$ at room temperature. Virions were serially diluted in media containing the same concentration of extract and plated on ED cells. Virus infectivity was evaluated $40 \mathrm{~h}$ later. Incubation of virions with aqueous extract has a profound impact on virion infectivity with $100 \mu \mathrm{g} / \mathrm{mL}$ of extract resulting in greater than 3000 -fold reduction in infectivity, indicating that the majority of the anti-viral effect seen is caused by the extracts interacting with the viral particles directly, rather than inhibiting later steps in the viral lifecycle (Fig.5B).

\section{Prunella vulgaris extracts inhibit virion binding to cells}

To determine if loss of virion infectivity was the result of reduced ability of virions to bind to permissive cells in the presence of Prunella extract, EIAV was incubated in the presence of the extracts on cells for $2 \mathrm{~h}$ at $4{ }^{\circ} \mathrm{C}$. These conditions allow binding, but prevent particle internalization. Unbound virions were removed and cells and virions associated with the cells were lysed. Lysates were examined for the presence of the viral protein, Capsid, to determine if the extracts reduced EIAV binding to the permissive cell population. When incubated with the DMSO control, EIAV Capsid protein was found in the lysates (Fig. 6). When the virions were exposed to the Prunella extracts, little or no Capsid was found to be associated with the lysates, indicating the extracts inhibit this initial step of viral replication.

\section{Virions treated with Prunella extract are intact}

Because the extracts were directly inhibitory to the viral particle binding to permissive cells, we wanted to determine if the extracts destroyed the viral particle thereby rendering them non-infectious and unable to bind to permissive cells. Immunoblots of density gradient separated, extract-treated viral particles were performed to evaluate the integrity of the virions. Viral Gag proteins were found in fractions 5, 6, 7 and 8 when the virions were treated with DMSO (Fig. 7A). Triton X-100 lysis of the virions resulted in the presence of Capsid protein in the top three fractions (Fig. 7B). The vast majority of Gag proteins was also found in fractions 5, 6, and 7 after treated with the Prunella extracts in a manner similar to that of the DMSO control (Fig. 7C). However, Gag proteins in Prunella treated samples were no longer present in fraction 8 and a modest percentage of these proteins was now found in the top of the gradient. These findings suggest that in general extracts did not destroy the virions or dramatically alter their density.
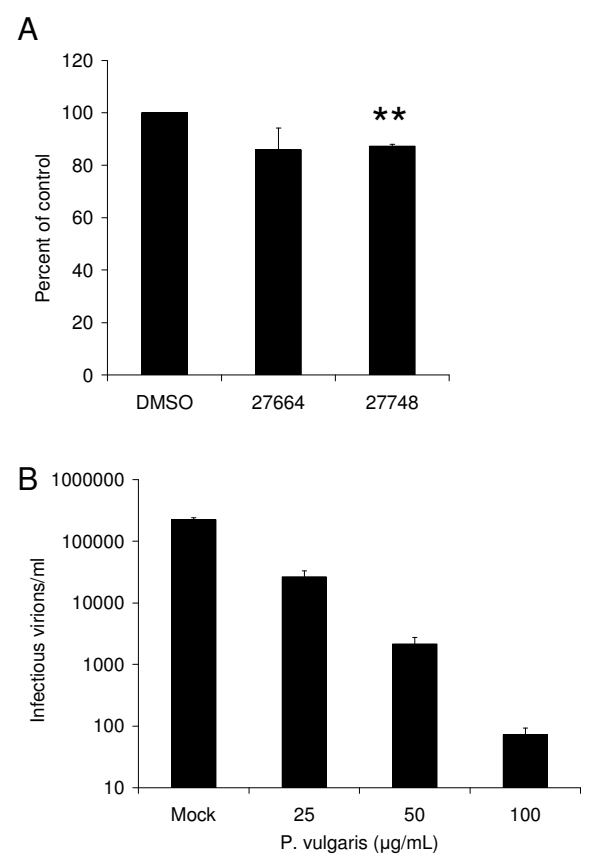

\section{Figure 5}

Prunella extracts inhibit EIAV infectivity primarily by acting on viral particles. A) Ability of cell-associated Prunella extracts to inhibit EIAV infection. Extracts were incubated with ED cells and removed prior to the addition of EIAV. EIAV infection was evaluated at $40 \mathrm{~h}$ following infection. B) Ability of Prunella extracts to inhibit EIAV. $2.2 \times 10^{5}$ EIAV WsU5 particles were incubated with 25,50 or $100 \mu \mathrm{g} / \mathrm{mL}$ extract from Prunella Ames 27664 extract for 10 minutes at room temperature. Viral stocks were diluted in media containing the appropriate concentration of extract and plated onto ED cells. Forty $h$ following infection the cells were fixed, immunostained for EIAV antigen and enumerated. Shown are the numbers of infectious virions $/ \mathrm{ml}$. Data represent the average and standard error of three experiments performed in duplicate (A) or triplicate (B). Extracts significantly reduced EIAV virion infectivity at all concentrations tested.

\section{Fractionation of whole-plant extracts}

Aqueous extracts of Prunella would be anticipated to contain abundant amounts of carbohydrates, phenolics and other water-soluble constituents. To begin to identify Prunella constituents within the aqueous extracts that are important for the anti-EIAV activity, the aqueous extract of Prunella Ames 27748 was separated by a Sephacryl 200 size-exclusion chromatography column into nine fractions. Both the distinct color of each of the fractions as well as LC/MS analysis of the fractions indicated that successful separation of Prunella constituents was achieved (data not shown). These fractions were resuspended in endotoxin-free water at a stock concentration of $100 \mathrm{mg} /$ $\mathrm{mL}$ and were tested for anti-EIAV activity. Surprisingly, 


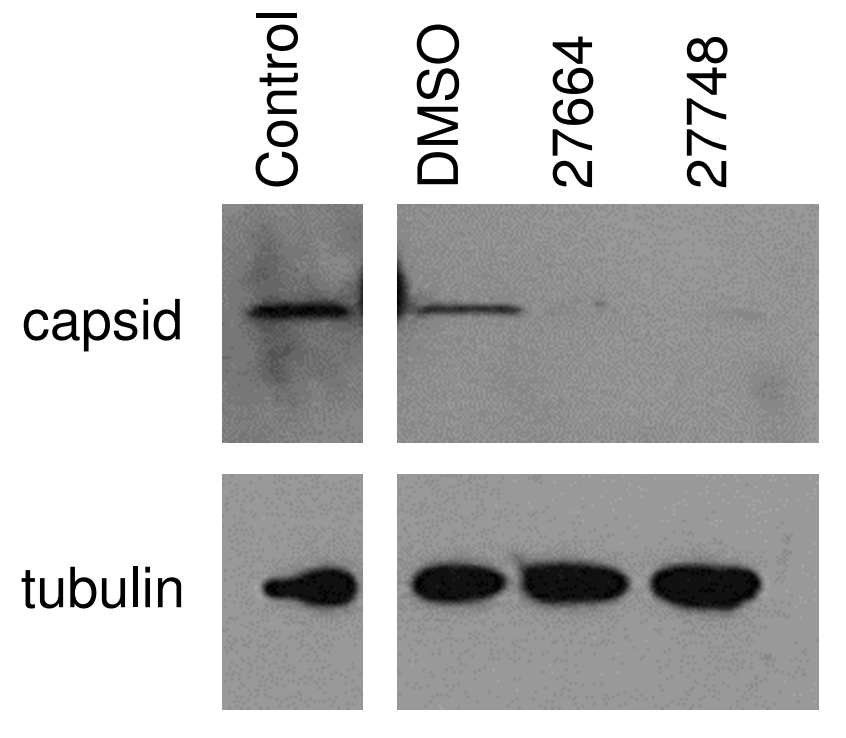

\begin{abstract}
Figure 6
Prunella extracts inhibit virion binding to cells. EIAV $_{\text {WSU5 }}$ virions mixed with the Prunella $(132 \mu \mathrm{g} / \mathrm{mL}$ of Ames 27664 or $126 \mu \mathrm{g} / \mathrm{mL}$ of Ames 27748) extracts or DMSO and added to ED cells at $4^{\circ} \mathrm{C}$ to promote binding but prevent internalization. After a two $h$ binding period, the unbound virions were removed, cells were washed and lysed. Cell lysates were immunoblotted for EIAV Gag proteins to detect bound virions, and tubulin served as a loading control. The experiment was repeated three times. A representative blot is shown.
\end{abstract}

fractions 3-9 contained potent anti-viral activity and fraction 2 had some inhibitory activity (Fig. 8A). Significant levels of cytotoxicity were observed with $100 \mu \mathrm{g} / \mathrm{mL}$ of fraction 7 . Cytotoxicity of fraction 7 was in contrast to what we had observed with similar concentrations of aqueous extract suggesting that either cytotoxic compounds were being concentrated in this fraction or that the separation of constituents resulted in greater cytotoxicity by some metabolites.

To further characterize the anti-viral constituents in the fractions, ethanol precipitation of the nine fractions was performed to separate ethanol-soluble and insoluble compounds. Constituents present in the sub-fractions were weighed and resuspended in endotoxin-free water at concentrations that represented the same ratio between the soluble and insoluble constituents present in the original fraction (see Table 1 for concentrations). A single ethanol-soluble fraction, Fraction 6, showed significant inhibition of EIAV (Fig. 8B). Ethanol-insoluble sub-fractions 4 and 9 displayed potent anti-EIAV activity (Fig. 8C). Interesting, the ethanol precipitation of fractions 2, 3, 5, 7 and 8 resulted in complete loss of anti-EIAV activity in either sub-fraction.

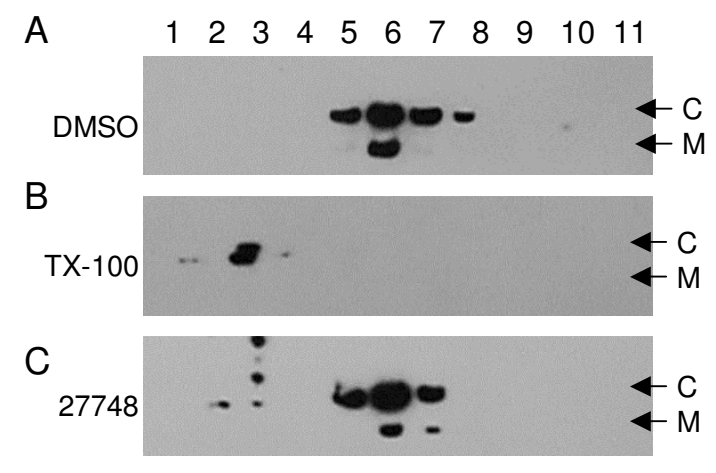

Figure 7

Prunella extracts do not destroy EIAV particles. EIAV ${ }_{\text {wSU5 }}$ virions were incubated with DMSO, Triton $X-100$ (0.5\%), or aqueous extracts of Prunella extract $(0.4 \%$ final concentration, $132 \mu \mathrm{g} / \mathrm{mL}$ of Ames 27664 or $126 \mu \mathrm{g} / \mathrm{mL}$ of Ames 27748) for I $h$ at $37^{\circ} \mathrm{C}$. The treated virions were density banded on a $20-60 \%$ sucrose gradient. Eleven fractions were collected and immunoblotted for EIAV Gag proteins, Capsid (C) and Matrix (M). The experiment was repeated three times and a representative blot is shown.

To determine if the ethanol precipitation destroyed the anti-viral activity or if multiple constituents that were separated during sub-fractionation were required for activity, we performed reconstitution experiments. The soluble and insoluble sub-fractions were added together at concentrations found in the original fractions and tested for anti-viral activity (Fig. 8D). The anti-viral activity seen in the original fraction 2 and 3 was lost after sub-fractionation and was not reconstituted. Reconstitution of fractions 4 and 9 did not enhance the anti-viral activity over that observed with the ethanol insoluble sub-fraction alone. Fraction 6 from the ethanol-soluble sub-fraction displayed anti-viral activity; however, after reconstitution, anti-viral activity was enhanced. Surprisingly, anti-viral activity was restored in fractions 5, 7 and 8 after reconstitution, suggesting synergy between constituents is required for the anti-viral activity of these fractions.

\section{Discussion}

This study identified anti-viral activity against the lentivirus EIAV in aqueous extracts of $P$. vulgaris. The primary mechanism of inhibition of viral replication targeted viral entry. The extracts dramatically reduced infectivity when incubated with the virions alone and interfered with the ability of virus to bind to permissive cells. However, entry of EIAV particles that were pre-bound to ED cells prior to exposure to the extract was also inhibited, suggesting the anti-viral activity was not limited to inhibition of viral binding, but also prevented additional external events 

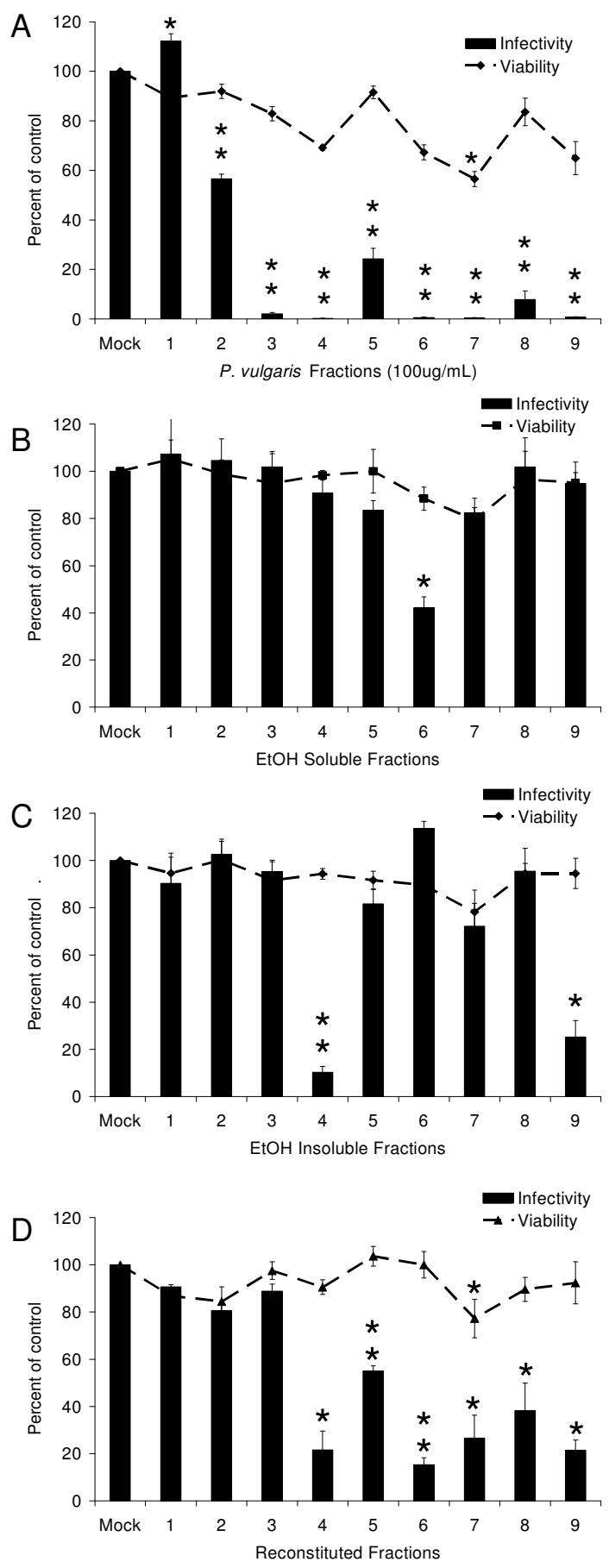

Figure 8

Fractionation segregates anti-viral constituents. ED cells were infected with ElAV $_{\text {WSU5 }}$ in the presence of the size exclusion fractions $(100 \mu \mathrm{g} / \mathrm{mL})(A)$, ethanol-soluble sub-fractions $(B)$, ethanol-insoluble sub-fractions $(C)$, or a combination of both the ethanol soluble and insoluble fractions at concentrations that reconstitute the original fractions (D). Forty $h$ following infection, cells were fixed and immunostained for viral antigen. Cell viability studies were performed in parallel. Cell viability and virus infectivity are shown as a ratio of the values in the presence of the fractions divided by the control. Data represent the average and standard error of three experiments performed in triplicate. ${ }^{*}, p<0.05 ; * *, p<0.00$ I. 
that are required for subsequent internalization and/or fusion. These extracts were not blocking specific interactions between EIAV and permissive cells such as the interaction of the gp90 glycoprotein and the cellular receptor ELR1 since the extracts effectively blocked infection of $E{ } A V_{\text {vMA-1c }}$ which can utilize a different cellular receptor [30].

Our fractionation studies indicated that numerous Prunella constituents were present in the aqueous extracts that have inhibitory activity against EIAV. To begin to identify the individual constituents responsible for the anti-viral activity, we separated the aqueous extracts by size-exclusion chromatography and subsequently separated those fractions into ethanol-soluble and insoluble components. Initial fractionation of the extract by size was not highly informative since 8 of the 9 fractions retained anti-viral activity. With five of these fractions, separation of constituents by ethanol precipitation resulted in loss of all activity; whereas, the ethanol-soluble material from one fraction had anti-viral activity and ethanol-insoluble sub-fractions from two other fractions were active. The anti-viral activity found in fractions 4 and 9 were ethanol-insoluble suggesting that carbohydrates may be responsible for the activity. The activity found in fraction 6 was ethanol-soluble and therefore is likely to be polyphenolic in nature. Of the five fractions where activity was lost upon sub-fractionation, activity was reconstituted when the ethanol-soluble and insoluble sub-fractions were combined to regenerate fractions 5, 7 and 8. Our findings demonstrated that synergy between ethanol-soluble and insoluble constituents is necessary for the antiviral activity in these fractions. Botanical constituents responsible for these anti-viral activities remain to be identified.

The extracts were found to effectively inhibit a range of EIAV strains from field isolates to a laboratory variant that can use a different cellular receptor to enter cells. The inhibition was observed in primary cells as well as a cell line. The breadth of the anti-viral activity of Prunella extracts was not unexpected since Prunella aqueous extract had previously been characterized to inhibit both the distantly related lentivirus HIV-1 and the unrelated DNA virus HSV-1 $[11,12,16,17]$. One of these studies identified a 10 $\mathrm{kDa}$ sulfated carbohydrate Prunellin from Prunella extracts that inhibited HIV-1 entry $[16,20]$. A carbohydrate of approximately that same size was responsible for inhibiting HSV-1 entry into cells [15]. While not definitively demonstrated, it is likely that Prunellin is also responsible for the anti-HSV-1 activity. Prunellin may be responsible for anti-EIAV activity found in ethanol-insoluble fraction 4 or 9 . However, the ability of ethanol-insoluble constituents present in two non-contiguous fractions to robustly inhibit infectivity implicates additional, cur- rently unidentified carbohydrates in the anti-viral activity against EIAV.

Extracts from other Lamiaceae species have been shown to bind to HIV-1 particles interfering with HIV-1 entry into permissive cells [22]. HIV-1 virions in the presence of extracts from lemon balm were shown to be denser in a sucrose gradient than virions in absence of extracts suggesting that extracts either altered the structure of the particle resulting in enhanced particle density or the constituents were bound to virions making the particles denser [22]. In our study, EIAV virions were not destroyed by treatment with the extracts. Nor did we observe a change in EIAV virion density as had been reported for HIV-1/lemon balm extracts [22]. While, it is likely that the Prunella extract binds to EIAV particles reducing productive, but non-specific interactions with target cells, this interaction did not significantly alter virion density. In addition, lemon balm extracts were not effective against HIV particles that were pre-bound to cells [22], a finding distinctly different from our observations that both binding events and post-binding events were affected by Prunella extracts.

The aqueous extracts from two of the Prunella accessions were significantly more inhibitory than extracts from two other accessions that were evaluated despite the fact that all four accessions were field grown in Iowa under similar conditions. The concentrations of the extracts used in this study could not account for this observation suggesting that there is extensive genotypic variation of Prunella in the field. The two extracts that were most effective were collected in areas of disturbed habitat adjacent to roads and are likely to have been recently introduced. In contrast, the extracts with weaker anti-EIAV activity were found in undisturbed, forested areas in North Carolina. Further genetic and metabolomic studies will be required to understand this potential constituent diversity within Prunella vulgaris.

\section{Abbreviations}

EIAV: equine infectious anemia virus; ED: equine dermis cells; eUVEC: equine umbilical vein endothelial cells; HIV-1: human immunodeficiency virus-1; HSV-1: herpes simplex virus-1; ELR1: equine lentivirus receptor-1; DMSO: dimethyl sulfoxide.

\section{Competing interests}

The authors declare that they have no competing interests.

\section{Authors' contributions}

$M A B$ was responsible for all of the EIAV studies that were performed. She organized and wrote the manuscript and generated the figures. MPW was responsible for the oversight of growth of the Prunella and participated in the har- 
vesting and processing of the plant material. JAM was responsible for the collection and documentation of the Prunella accessions, the planting, maintenance of the plants, harvesting and processing of the Prunella. PM was responsible for the oversight of the Prunella fractionation and ethanol precipitations. $\mathrm{CH}$ was responsible for performing all fractionation of the Prunella. LR and BN were responsible for GC/MS and LC/MS analysis of the fractions and sub-fractions. WM was responsible for oversight of the project including design and coordination of the study. She was principally responsible for the editing of the manuscript.

\section{Additional material}

\section{Additional file 1}

Supplementary figure 1. Water extracts of $\mathrm{P}$. vulgaris inhibit lentiviral infectivity with low cell toxicity.

Click here for file

[http://www.biomedcentral.com/content/supplementary/1743-

422X-6-8-S1.ppt]

\section{Acknowledgements}

This publication was made possible by grant number 9P50AT004I55-06 from the National Center for Complementary and Alternative Medicine (NCCAM) and Office of Dietary Supplements (ODS). Its contents are solely the responsibility of the authors and do not necessarily represent the official views of the NIEHS, NCCAM, or NIH. Mention of commercial brand names does not constitute an endorsement of any product by the U.S. Department of Agriculture or cooperating agencies.

\section{References}

I. Chiej R: Encyclopaedia of Medicinal Plants. MacDonald 1984

2. Hamada T: [Studies on the medicinal plant in the "Sambutsucho" of Higo Province possessed by the Kumamoto clan (II): on the medicina herbs]. Yakushigaku Zasshi 1993, 28:63-72.

3. Fang X, Yu MM, Yuen WH, Zee SY, Chang RC: Immune modulatory effects of Prunella vulgaris $L$. on monocytes/macrophages. Int J Mol Med 2005, 16: I 109-1II6.

4. Fang $X$, Chang RC, Yuen WH, Zee SY: Immune modulatory effects of Prunella vulgaris L. Int J Mol Med 2005, I 5:49|-496.

5. Ryu SY, Oak MH, Yoon SK, Cho DI, Yoo GS, Kim TS, Kim KM: Antiallergic and anti-inflammatory triterpenes from the herb of Prunella vulgaris. Planta Med 2000, 66:358-360.

6. Skottova N, Kazdova L, Oliyarnyk O, Vecera R, Sobolova L, Ulrichova $\mathrm{J}$ : Phenolics-rich extracts from Silybum marianum and Prunella vulgaris reduce a high-sucrose diet induced oxidative stress in hereditary hypertriglyceridemic rats. Pharmacol Res 2004, 50: 123-130.

7. Psotova J, Kolar M, Sousek J, Svagera Z, Vicar J, Ulrichova J: Biological activities of Prunella vulgaris extract. Phytother Res 2003, I 7: 1082-1087.

8. Won J, Hur YG, Hur EM, Park SH, Kang MA, Choi Y, Park C, Lee KH, Yun Y: Rosmarinic acid inhibits TCR-induced T cell activation and proliferation in an Lck-dependent manner. Eur J Immunol 2003, 33:870-879.

9. Ahn SC, Oh WK, Kim BY, Kang DO, Kim MS, Heo GY, Ahn JS: Inhibitory effects of rosmarinic acid on Lck SH2 domain binding to a synthetic phosphopeptide. Planta Med 2003, 69:642-646.

10. Valentova K, Truong NT, Moncion A, de Waziers I, Ulrichova J: Induction of glucokinase mRNA by dietary phenolic compounds in rat liver cells in vitro. J Agric Food Chem 2007, 55:7726-7731.
II. Chiu LC, Zhu W, Ooi VE: A polysaccharide fraction from medicinal herb Prunella vulgaris downregulates the expression of herpes simplex virus antigen in Vero cells. J Ethnopharmacol 2004, 93:63-68.

12. Kageyama S, Kurokawa M, Shiraki K: Extract of Prunella vulgaris spikes inhibits HIV replication at reverse transcription in vitro and can be absorbed from intestine in vivo. Antivir Chem Chemother 2000, II:157-164.

13. Nolkemper S, Reichling J, Stintzing FC, Carle R, Schnitzler P: Antiviral effect of aqueous extracts from species of the Lamiaceae family against Herpes simplex virus type $I$ and type 2 in vitro. Planta Med 2006, 72:1378-| 382.

14. Xu HX, Lee SH, Lee SF, White RL, Blay J: Isolation and characterization of an anti-HSV polysaccharide from Prunella vulgaris. Antiviral Res 1999, 44:43-54.

15. Zhang Y, But PP, Ooi VE, Xu HX, Delaney GD, Lee SH, Lee SF: Chemical properties, mode of action, and in vivo anti-herpes activities of a lignin-carbohydrate complex from Prunella vulgaris. Antiviral Res 2007, 75:242-249.

16. Yao XJ, Wainberg MA, Parniak MA: Mechanism of inhibition of HIV-I infection in vitro by purified extract of Prunella vulgaris. Virology 1992, 187:56-62.

17. Liu S, Jiang S, Wu Z, Lv L, Zhang J, Zhu Z, Wu S: Identification of inhibitors of the HIV-I gp4 I six-helix bundle formation from extracts of Chinese medicinal herbs Prunella vulgaris and Rhizoma cibotte. Life Sci 2002, 7I:I779-I79I.

18. Au TK, Lam TL, Ng TB, Fong WP, Wan DC: A comparison of HIVI integrase inhibition by aqueous and methanol extracts of Chinese medicinal herbs. Life Sci 200I, 68:1687-1694.

19. Lam TL, Lam ML, Au TK, Ip DT, Ng TB, Fong WP, Wan DC: A comparison of human immunodeficiency virus type-I protease inhibition activities by the aqueous and methanol extracts of Chinese medicinal herbs. Life Sci 2000, 67:2889-2896.

20. Tabba HD, Chang RS, Smith KM: Isolation, purification, and partial characterization of prunellin, an anti-HIV component from aqueous extracts of Prunella vulgaris. Antiviral Res 1989, I I:263-273.

2I. Kim HK, Lee HK, Shin CG, Huh H: HIV integrase inhibitory activity of Agastache rugosa. Arch Pharm Res 1999, 22:520-523.

22. Geuenich S, Goffinet C, Venzke S, Nolkemper S, Baumann I, Plinkert $P$, Reichling J, Keppler OT: Aqueous extracts from peppermint, sage and lemon balm leaves display potent anti-HIV-I activity by increasing the virion density. Retrovirology 2008, 5:27.

23. O'Rourke K, Perryman LE, McGuire TC: Antiviral, anti-glycoprotein and neutralizing antibodies in foals with equine infectious anaemia virus. J Gen Virol 1988, 69:667-674.

24. Carpenter S, Chesebro B: Change in host cell tropism associated with in vitro replication of equine infectious anemia virus. J Virol 1989, 63:2492-2496.

25. Maury W, Wright PJ, Bradley S: Characterization of a cytolytic strain of equine infectious anemia virus. I Virol 2003, 77:2385-2399.

26. Payne SL, Rausch J, Rushlow K, Montelaro RC, Issel C, Flaherty M, Perry S, Sellon D, Fuller F: Characterization of infectious molecular clones of equine infectious anaemia virus. J Gen Virol 1994, 75:425-429.

27. Maury WJ, Carpenter S, Graves K, Chesebro B: Cellular and viral specificity of equine infectious anemia virus Tat transactivation. Virology 1994, 200:632-642.

28. Brindley MA, Maury W: Endocytosis and a low-pH step are required for productive entry of equine infectious anemia virus. J Virol 2005, 79:|4482-|4488.

29. Brindley MA, Maury W: Equine infectious anemia virus entry occurs through clathrin-mediated endocytosis. J Virol 2008, 82:1628-1637.

30. Brindley MA, Zhang B, Montelaro RC, Maury W: An equine infectious anemia virus variant superinfects cells through novel receptor interactions. J Virol 2008, 82: 1628-37.

31. Weakley AS: Flora of the Carolinas, Virginia, and Georgia, and Surrounding Areas Chapel Hill, NC: University of North Carolina Herbarium (NCU), North Carolina Botanical Garden, University of North Carolina at Chapel Hill; 2007. 